1 Why a biopsychosocial approach is very much needed in studying sexual

\section{effects of contraception}

Running head: Sexual motivation and contraception

Els Elaut

Center for Sexology and Gender, University Hospital Ghent

De Pintelaan 185, Ghent, Belgium

003293322159, els.elaut@ugent.be 
The FDA-approval of the first oral contraceptive on May $9^{\text {th }} 1960$ stirred the public and scientific debate. Initially, concerns regarding sexual effects in women were limited. After decades of largescale use of oral contraception (OC) in over 100 million women worldwide, it is amazing how little we know about the effects on women's sexuality. In the late 1980s, the Human Reproduction Program of the WHO appointed John Bancroft to conduct a series of studies into OC and sexual health ${ }^{(1-4)}$. The author will discuss three main conclusions of this series, supplemented with recent additions in the field, to show why a biopsychosocial approach in this area is urgently needed.

To be able to put studies on $O C$ use and female sexual desire (or 'sexual interest' or 'sexual motivation') in a correct perspective, the author wishes to refer to a leading theoretical, biopsychosocial model called the incentive motivation model ${ }^{(5)}$ (Figure 1). It is stated that sexual desire or sexual motivation (in both women and men!) is the result of a complex and layered process. They consider that sexual motivation typically emerges when a functional 'sexual system' (influenced by receptors, sex steroids, genetic sensitivity etcetera) is activated by an internal or external stimulus that is sexually meaningful to the individual concerned. This stimulus can be visual, olfactory or otherwise, and its valence depends on the sexual memory (attitudes, norms and previous sexual experiences) of the person (Figure 1). For example, some individuals will find a certain smell or sound sexually stimulating since it reminds them of earlier positive experiences with that smell or sound, in their personal memory associated with a sexual reward. This same stimulus can be experienced as neutral or even negative by another person, depending on the specific associations in that persons sexual memory ${ }^{(5)}$.

\section{OC use can result in lower sexual motivation, although not in all users}

Returning to the WHO-studies above, firstly, they point towards a reduction in sexual desire (or sexual motivation), at least in some OC starters ${ }^{(3 ; 4)}$. A systematic review has found around $15 \%$ of OC users to experience negative effects on sexual desire ${ }^{(6)}$, although it remains unclear as to how this group differs from women who experience no or a positive change in sexual desire. Since the first 
studies, the iatrogenic hypo-androgenism hypothesis has been put forward frequently; this hypothesis states that the OC-induced decrease in free testosterone (FT) could be responsible for sexual side effects. Until today, no methodologically sound study could find a causal link between this FT decrease and lower sexual motivation. One large prospective study in pill starters found a relation between the extent of diminished FT and the frequency of sexual thoughts after three months of OC use. Most women, however, did not experience a decreased sexual motivation, despite a substantial decrease in $\mathrm{FT}^{(7)}$.

Based on these and other observations, John Bancroft proposed his desensitization hypothesis: women are not only sensitive to lower androgen levels than men, they also show greater interindividual behavioral variations in their response to $\mathrm{FT}^{\left({ }^{(8)}\right.}$. So, more genetic variability (e.g. in androgen receptor sensitivity) could become evident at lower FT levels and would be manifested as a greater variability in behavioral responsiveness. One Canadian study found partial confirmation in their observation that women with a more 'masculine' 2D:4D ratio (second digit: fourth digit, an anthropometrical indicator of androgen exposure) are more at risk for $\mathrm{OC}$ side effects. Women with a lower 2D:4D ratio (usually seen in men) more often report a history of emotional and sexual side effects with $\mathrm{OC}$ use ${ }^{(9)}$. A more recent study found that sexual motivation in users of hormonal contraception is related to genetic sensitivity (measured as a variation of the androgen receptor gene on the X-chromosome). Further, women also indicated to experience a stronger motivation while using the vaginal ring, when their partner also reported stronger sexual motivation for them, and in the absence of negative mood ${ }^{(10)}$. These results confirm the incentive motivation model: both genetic factors (influencing the sexual arousability or sensitivity of the sexual system, left in Figure 1), as context (sexual motivation partner) and individual factors (mood) (both right in Figure 1), determine the sexual motivation of users of hormonal contraception. Based on these findings, one could advocate a prospective biopsychosocial approach in studying sexual effects of OC, or more broadly, hormonal contraception. 


\section{Sexual and emotional side effects are the most important reasons to discontinue OCs}

Second, sexual side effects not only exist, sexual and emotional side effects are the most important reasons to discontinue OCs. While prospective studies exist on the reasons for discontinuing OCs, they often only mention self-reported side effects ${ }^{(11)}$ or do not include sexual variables. To the author's knowledge, only one study assesses the self-reported side effects in a group of pill starters (women who had never used OC), while also prospectively and repeatedly (for 12 months) assessing physical and emotional well-being, perimenstrual symptoms, sexual interest, enjoyment and frequency of sexual activity ${ }^{(2)}$. In this group, $47 \%$ discontinued and $14 \%$ switched to another OC. The authors note that only $8 \%$ of women specifically report sexual side effects as a reason to discontinue OC use. However, a logistic regression (explaining $87 \%$ of the variance in outcome) on these data show emotional (worsening of PMS) and sexual side effects (decreased frequency of sexual thoughts and diminished sexual arousability) to be the best predictors of OC discontinuation ${ }^{(2)}$. This very different result between the self-report and the regression model should make us consider: why do women hesitate to report sexual side effects as reasons for discontinuation, while they are shown to be highly relevant and predictive of (dis)continuation? Possibly, an absence of information on potential sexual side effects during contraception counseling, as well as the general societal taboo on talking about sex could be hindering women's self-report . Clearly, providers should 'model' an attitude of talking about sex and sexual side effects, not only when providing a first OC prescription, but also when inquiring for possible side effects afterwards.

\section{Sexual motivation might get 'flattened out' during the contraceptive cycle}

Finally, the pattern of sexual motivation in OC users might differ from that of women not using hormonal contraception. Cycling women experience a peak in sexual motivation around midcycle $^{(12,13)}$. One retrospective study in a large sample of 4112 women (non-pill users, $\mathrm{N}=3252$, and pill users, $\mathrm{N}=860$ ) brought to light a pattern with less peaks and troughs in sexual motivation during pilldriven cycles, compared to women in non-pill, menstrual cycles ${ }^{(1)}$. A more recent, prospective study 
looked at the cyclical patterns of sexual desire and the frequency of sexual activity in OC users ${ }^{(14)}$. Its findings confirm those of earlier retrospective research: no mid-cycle peak is seen, leading to the conclusion that sexual motivation might indeed be 'flattened out' during pill-driven cycles. A more positive affect in the women is related to stronger sexual motivation, both pertaining to the interest in solitary sexual behavior (masturbation) as the interest in partnered sexual behavior.

\section{Conclusion}

Although genetic factors appear to have relevance, research on the sexual motivation in contraception users should look further than the biological 'arousability' of the sexual system by measuring only testosterone levels. Feeling desired by a partner and experiencing a positive affect clearly are psychosocial conditions making it possible for stimuli to activate the sexual system, and sexual motivation to emerge. When it comes to studying contraception and female sexuality, the interaction between genetics, hormones, mood, relationship and personality is paramount. Biopsychosocial models such as the incentive motivation theory could help researchers in broadening our understanding of this field.

\section{Acknowledgements}

Disclosure of interests

Contribution of authorship

Details of ethical approval

Funding
N/A

None

Sole author

N/A

N/A 
(1) Warner P, Bancroft J. Mood, sexuality, oral contraceptives and the menstrual cycle. J Psychosom Res 1988;32:417-27.

(2) Sanders SA, Graham CA, Bass JL, Bancroft J. A prospective study of the effects of oral contraceptives on sexuality and well-being and their relationship to discontinuation. Contraception 2001;64:51-8.

(3) Graham CA, Sherwin BB. The relationship between mood and sexuality in women using an

(4) Graham CA, Ramos R, Bancroft J, Maglaya C, Farley TM. The effects of steroidal

(5) Both S, Everaerd W, Laan E. Desire emerges from excitement. A psychophysiological contraceptives on the well-being and sexuality of women: a double-blind, placebocontrolled, two-centre study of combined and progestogen-only methods. Contraception $1995 ; 52: 363-9$. perspectieve on sexual motivation. In: Janssen E, editor. The psychophysiology of sex.Bloomington: Indiana University Press; 2007. p. 325-62.

(6) Pastor Z, Holla K, Chmel R. The influence of combined oral contraceptives on female sexual desire: a systematic review. Eur J Contracept Repr Health Care 2013;18:27-43.

(7) Graham CA, Bancroft J, Doll HA, Greco T, Tanner A. Does oral contraceptive-induced reduction in free testosterone adversely affect the sexuality or mood of women? Psychoneuroendocrinology; 2007,32:246-255. 
(8) Bancroft J. Sexual effects of androgens in women: some theoretical considerations. Fertil Steril 2002;77:S55-S59.

(9) Oinonen KA. Putting a finger on potential predictors of oral contraceptive side effects: 2D:4D and middle-phalangeal hair. Psychoneuroendocrinology 2009;34:713-729.

(14) Elaut E, Buysse A, De SP, Gerris J, De CG, T'Sjoen G. Cycle-Related Changes in Mood, Sexual Desire, and Sexual Activity in Oral Contraception-Using and Nonhormonal-ContraceptionUsing Couples. J Sex Res 2016;53:125-36.

(10) Elaut E, Buysse A, De SP, De CG, Gerris J, Deschepper E, et al. Relation of androgen receptor sensitivity and mood to sexual desire in hormonal contraception users. Contraception 2012;85:470-9.

(11) Rosenberg MJ, Waugh MS. Oral contraceptive discontinuation: a prospective evaluation of frequency and reasons. Am J Obstet Gynaecol 1998; 179: 577-582.

(12) Roney JR, Simmons ZL. Hormonal predictors of sexual motivation in natural menstrual cycles. Horm Behav 2013 Apr;63(4):636-45.Bancroft J. Human sexuality and its problems. 3 ed. Oxford: 2009.

(13) Bullivant SB, Sellergren SA, Stern K, Spencer NA, Jacob S, Mennella JA, et al. Women's sexual experience during the menstrual cycle: identification of the sexual phase by noninvasive measurement of luteinizing hormone. J Sex Res 2004;41:82-93. 


INDIVIDUAL:
sexual system with
'central arousability', influenced by
e.g. receptors, sex steroids

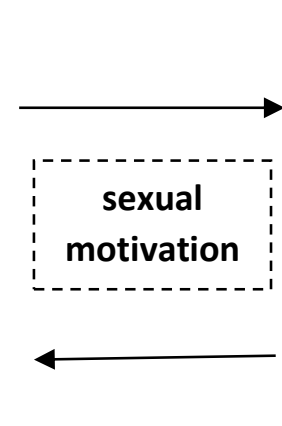

\begin{tabular}{|c|}
\hline CONTEXT: \\
meaningful interal/external \\
sexual stimuli, stemming from \\
individual learning history \\
\hline
\end{tabular}

158

Figure 1. Non-exhaustive overview of factors influencing activation of sexual motivation. Based on 160 Both, Everaerd, \& Laan, 2007. 